\title{
Mediating and Moderating Role of Organizational Ambidexterity and Innovative Climate among Leadership Styles and Employee Performance
}

Rana Zain-ul-Abidin ${ }^{1}$, Rabia Qammar ${ }^{2 *}$

${ }_{1,2}$ ILMA, University formerly IBT, Karachi, Pakistan

\author{
*Corresponding Author: Rabia Qammar, ILMA, University formerly IBT, Karachi, Pakistan \\ rabiaqmr9@yahoo.com
}

\begin{abstract}
This research seeks to examine how transformational leadership and ambidextrous leadership impact on employee performance. The study focuses on the mediating role of organizational ambidexterity and moderating role of innovation climate, in influencing the relationship both directly and indirectly with employee performance. The proposed model will be tested with data collected from a large stratified random sample of 1000 software house's employees from a population comprising of 3348 information technologies companies in Pakistan. Results, using statistical analysis techniques, are expected to indicate that organizational ambidexterity and innovation climate will mediate and moderate among transformational leadership and ambidextrous leadership, with employee performances.
\end{abstract}

Keywords: Transformational Leadership, Ambidextrous Leadership, Innovation Climate

\section{INTRODUCTION}

Innovation in information technology firm has develop a main driver of creating a competitive advantage (Hamel, 2006; Teece, 2010; Rapp et al., 2019). It has led to changes in the ways IT companies compete in a single industry and has had a direct effect on their ability to survive. The IT organization that does not innovate will probably not stay in the market for long (Dess \& Picken, 2000; O'Reilly \& Tushman, 1997, Diesel \& Scheepers, 2019).

Innovation is more than newness, inventions, creativity (Shavinina, 2011), or tools that can be used to enhance the brand image of an IT company. It generates new options for businesses and expands their entrepreneurial possibilities (Schmitt, 2012). Coming up with new ideas and strategies is easy for most IT companies. However, moving from ideation to commercialization in the business innovation process is challenging. IT companies often fail when attempting to work though the various stages of the innovation strategies (Berends, Smits, Reymen \& Podoynitsyna, 2016; Rapp et al., 2019).

Scholars and managerial practitioners have identified leadership behaviours as the most influential drivers of innovation climate (Lawton \& Weaver, 2010). Executives can create a climate within their organizations that support innovation (Soken \& Barnes, 2014). This includes developing the skill sets necessary for the innovation process such as forming structures, allocating resources, putting processes 
in the place, creating effective learning environments, being open to outside ecosystems, and accepting failure and considering it as a part of learning (Morris, Kuratko \& Covin, 2010).

Managerial scholars argue that the notion of an innovative leader is different from that of an innovation leader. However, some in academia and material practices still misunderstand the difference between these two concepts (Horth \& Buchner, 2009). The concept of an innovative leader relates to the leader's skills and traits. This type of leader is a source of creativity who can bring in new thinking and prescribe different actions regarding how to lead, manage, and move forward with work. An innovative leader can think of different ways to overcome organizational challenges or deal with a scarcity of information (Loewe \& Chen, 2007). In contrast, an innovation leader focuses on creating an organizational environment where there is a climate of innovation that supports innovation within teams. In this environment, employees can implement innovative practices which lead to the development of new products or services (Elkins \& Keller, 2003). In addition, an innovation leader does not just hire creative resources. Rather, an innovation leader helps teams to think of new ways to capture value, work within the constraints of resource to develop and manage processes and achieve a competitive advantage and ultimately organizational survival (Horth \& Buchner, 2009). Overall, a growing knowledge of leadership practices and innovation is evident among those in the field of management and in academic literature (Drejer, 2006). Scholars suggest that innovation leaders must possess a mix of leadership skills that can interact with each other if they are to produce high quality of innovation outcomes (Sammut \& Paroutis, 2013). Thus, innovation leaders need to identify and develop the skills that are appropriate for impacting innovation. After all, they are the ones who are responsible for infusing their organizations with practices that fosters employee performance (Soken \& Barnes, 2014).

\section{RESEARCH QUESTIONS}

These research questions are intended to examine the proposed relationships: -

1. What is the link between the CEO Transformational Leadership and employee performance?

2. What is the link between the Ambidextrous Leadership and employee performance?

3. Does Innovation Climate mediates among the CEO Transformational Leadership and employee performance?

4. Does Innovation Climate mediates among Ambidextrous Leadership and employee performance?

5. Does Organizational Ambidexterity moderates among CEO Transformational Leadership and employee performance?

6. Does Organizational Ambidexterity moderates among Ambidextrous Leadership and employee performance?

\section{SIGNIFICANCE OF THE STUDY}

This study will extend the existing body of knowledge on CEO transformational leadership and ambidextrous leadership relationships by investigating the mediation of Innovation climate and, moderation of organizational ambidexterity with employee performance. Moreover, it will sensitize practitioners that how CEO transformational leadership and ambidextrous leadership result in employee performance both directly and when mediated by innovation climate and moderated by Organizational Ambidexterity inform them about the remedial measures against the effects of leaderships on innovation It will also provide a basis for further investigation on different dimensions of leadership in an organization. 


\section{PURPOSE OF THE STUDY}

The purpose of this study is to investigate the direct positive link between CEO transformational leadership, ambidextrous leadership and employee performance, also check the triangular effects of innovation climate (mediator) and organizational Ambidexterity (moderator) among CEO transformational leadership, ambidextrous leadership and employee performance. The unit of analysis of this study is IT companies in Pakistan.

\section{PRELIMINARY LITERATURE REVIEW}

\section{THE ROLE OF CEO TRANSFORMATIONAL LEADERSHIP}

Transformational forerunners are depicted as "moving the devotee past prompt personal matters through romanticized impact (appeal), motivation, scholarly incitement, or individualized thought" (Bass, 1999). They can convey an image of what the future will resemble if their association's objectives are accomplished. The energy and responsibility of devotees develops in light of the fact that their pioneers cause their association's objectives to appear to be lively, alive, drawing in, and even unmistakable. The transformational leadership style supports investigating new business ideas planned for accomplishing achievements in development results (Giesen, Riddleberger, Christner and Bell, 2010). It encourages achievements at the authoritative level by concentrating on investigation, cultivating a learning atmosphere, advancing security, being available to differing thinking, taking into consideration botches, and engaging workers using opening practices. At the point when these components cooperate in an association, advancement execution can expand (Nemanich and Vera, 2009).

\section{THE ROLE OF AMBIDEXTROUS LEADERSHIP}

Ambidextrous leadership is a new leadership theory which was put forth by German strategy professors Rosing, Frese, and Bausch (2011). Funded by Volkswagen information Technology Company, Rosing et al. conducted a comprehensive research study which implemented a metanalysis of existing literature that linked leadership effectiveness with innovation performance. Rosing et al. focused on determining the behaviors that influenced business innovation most effectively and looked specifically at the behaviors of leaders who had direct contact with innovation teams. The dilemma related exclusively to the two ends natures of the innovation process which are creativity and implementation. They require opposing and contradicting leading behaviors (i.e., opening and closing behaviors) (Probst, Raisch \& Tushman, 2011).

Ambidextrous Leadership is a management function where a person in a position of responsibility exerts a level of influence over subordinates to achieve the goals of an organization (Bhatti, Maitlo, Shaikh, Hashmi, \& Shaikh, 2012). The term "Ambidextrous leadership" refers to the general set of characteristics, skills, behavior, and managerial attitudes that leaders use to encourage compliance (Bass, 2009). An Ambidextrous leadership style may influence the extent which the members of the management team respect their subordinates, whether they operate with honesty and integrity, how they promote efficiency, and whether they have open lines of communication with employees (Kleinman, 2010). Ambidextrous leadership style can significantly influence how employees feel about their working environment, and it may affect overall employee job satisfaction. Therefore, the complexity of innovation leadership is feed by the overlapping roles and activities that depend on the hierarchy of an organization. Leaders should employ a transformational leadership style to influence organizational innovation whereas team leaders should use ambidextrous leadership to respond to variations in innovation outcomes (Zacher \& Wilden, 2014). 


\section{The Mediating Role of Organizational AMBideXterity}

The concept of an ambidextrous organization was first introduced by Tushman and O'Reilly in 1996. The term ambidextrous ordinarily means having the ability to use both the right and left hand equally well for writing or doing other manual tasks. Balancing current business performance with futuristic opportunities is a challenge. However, if it can be done, it can increase a company's ambidexterity (Probst, Raisch \& Tushman, 2011). Usually, the strategic leadership of an organization is at the core of an exploration activity. The organization's managers focus on short-term objectives using controlled activities such as quality checking, budgeting, and efficiency programs for current business (Zaleznik, 2003). The company's sustainability depends on the TMT being aware that ambidexterity is the element that will allow it to explore the future and exploit the present in a balanced manner (Lubatkin, Simsek, Ling \& Veiga 2006).

Studies show that senior executives who possess transformational leadership behaviors can contribute significantly to an organization's ambidexterity (Jansen, George, Van Den Bosch \& Volberda, 2008) and influence organizational performance significantly (Samad, 2012). They can handle short- and long-term vision to increase the organization ambidexterity. Senior executives can contribute to the organization ambidexterity using both transformational leadership behaviors, which drives exploration activities (Jansen, Vera, \&Crossan, 2009), and transactional leadership behaviors, which drive exploitation activities. Both styles are supported by the organizational climate supporting innovation (Garcia-Morales, Matias-Reche \& HurtadoTorres, 2008). In general, there are many researchers who have discussed ambidexterity potential in organizations by showing the positive influence on organizational success (Junni, Sarala, Taras \& Tarba, 2013). However, organizations struggle in using exploration and exploitation simultaneously (Andriopoulos \& Lewis, 2009; Simsek, Heavey, Veiga \& Souder, 2009). Previous studies are ambiguous in the way they explain how to achieve ambidexterity in different contexts (O'Reilly \& Tushman, 2013). For example, some studies show that ambidexterity can work not only at the organizational level construct, but also at the team and individual levels (Birkinshaw \& Gupta, 2013; Bonesso, Gerli \& Scapolan, 2014; Rosing \& Zacher, 2016).

\section{The Moderating Role of InNovation Climate}

Soken and Barnes (2014) claim that in organizations executives benefit from innovation environments. However, innovation that empowers authoritative atmosphere isn't made by some coincidence. It is the consequence of an association's methodology, a strong culture, and powerful pioneers who are eager to gain from disappointment. As per an overall overview directed by Barsh, Capozzi and Davidson (2008), over $94 \%$ of officials demonstrated that individuals and atmosphere are the two most significant drivers of advancement in associations. They put human capital at the focal point of their methodologies and know that the atmosphere of an association can promote or poison creativity and innovation. However, having an organizational climate that only rewards innovative ideas and behaviors is not enough (Sternberg, 2006). Organizational climate should also support open communication and multi-level collaboration across functional teams; work to empower teams by getting support from company executives; encourage risk taking, flatter organization structures, feedback, and intensive collaboration with stakeholders; and let stakeholders participate in the innovation process and its outcomes (Neely \& Hii,1998).

\section{UNDERPINNING THEORIES}

This investigation tries to hold up substantive input to two reinforcement theories, paradox theory and leadership theory. The structure chains both theories to promote employee performance through the use of intellectual mindset and leadership style. 


\section{PROPOSED THEORETICAL FRAMEWORK}

The proposed multi-level modelling analysis framework below illustrates how innovation can be driven and fostered in organizations. It shows that the influence that leadership style has on innovation performance depends on the organization's hierarchal context. In an organization's top-level management team, the CEO has an important role in promoting organizational innovation (Makri \& Scandura, 2010). CEO transformational leadership (independent variable \#1) is the best to foster and drive employee performance (dependent variable). At the lower levels which are the team levels, it is best for the team leader to use the ambidextrous leadership style. The ambidextrous leadership style is defined as the opening and closing behaviors (independent variable \#2). These two behaviors together foster and influence employee performance. Finally, both of these relationships will have a higher positive impact on innovation outcomes as long as there is a supportive organizational climate for innovation (the moderator variable). The organizational ambidexterity (the mediating variable) plays an interacting role between CEO transformational leadership and ambidextrous leadership.

Based on the preliminary literature review, Fig.1 portrays the underlying relationship among of CEO Transformational Leadership, Ambidextrous Leadership, organizational ambidexterity, innovative climate and employee performance: -

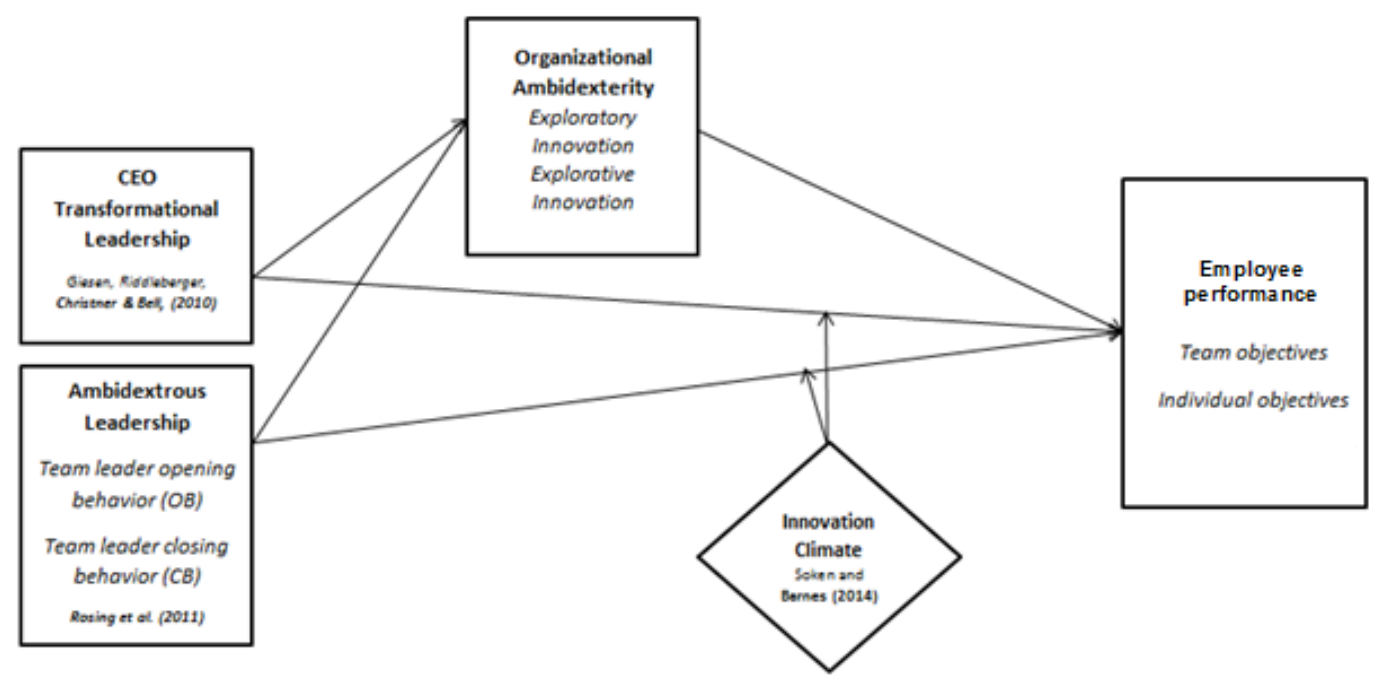

\section{HYPOTHESES DEVELOPMENT}

Following hypotheses are proposed: -

H1: CEO Transformational Leadership will significantly relate to employee performance.

H2: Ambidextrous Leadership will significantly relate to employee performance.

H3: Innovation Climate will significantly mediates among CEO Transformational Leadership and employee performance.

H4: Innovation Climate will significantly mediates among Ambidextrous Leadership and employee performance.

H5: Organizational Ambidexterity will significantly moderates among CEO Transformational Leadership and employee performance.

H6: Organizational Ambidexterity will significantly moderates among Ambidextrous Leadership and Employee performance. 


\section{RESEARCH METHODOLOGY}

This will be a non-contrived field study which will follow relational design. The relationship between variables of study will be investigated without any planned intervention. Being a cross sectional study, the data will be collected in one point in time which will describe the link between variables at that particular time.

Population for this study consists of software house employees having a minimum of 2 years job experience in IT companies in Pakistan. Total population is estimated at 3348 (Nadeem, 2018). The research subjects would be the individual employees of these IT companies. A large sample size of 1000 will be selected so as to detect even if the effect size is small (MacKinnon et al., 2002), from organizations having large number of employees from each strata using Stratified Simple Random Sampling.

In order to identify design issues if any, verify data measurement instruments, do preliminary hypotheses testing, and fine tune data analysis procedures for main study, a pilot study will be conducted using the study design parameters decided for the main study with a different but a small sample size of 50 subjects.

The data would be collected through self-administered questionnaires after giving ample time to respondents to fill in their responses. For improving response rate and understanding for those respondents who do not understand English language explicitly, the feedback form would be translated from English to Urdu and back with caution (McGorry, 2000). Following scales have been adopted to measure various constructs of the study.

1. CEO Transformational leadership adopted from Giesen, Riddleberger, Christner \& Bell, (2010). The instrument has 14 items measuring the construct on a five categories Likert Scale ranging from 1 (strongly disagree) to 5 (strongly agree).

2. Ambidextrous Leadership adopted from Rosing et al. (2011) having 3 items with scale reliability of 0.91 .

3. Organizational Ambidexterity adopted from Rosing \& Zacher, (2016). The scale available free for use by researchers and has 0.83 scale validity of 16 items.

4. JS would be measured using the instrument devised by Alves, Márcia Guimarães de Mello et al. (2004). The instrument has 17 items measuring the construct on a five categories Likert scale ranging from 1 (strongly disagree) to 5 (strongly agree). Has a reliability coefficient of 0.89 .

5. Innovation Climate adopted from Soken and Barnes (2014) has 12 items. The reliability of scale is 0.85 .

6. Overall employee performance adopted from Macey, \& Saks, (2015). The scale has a reliability index of 0.88 .

\section{DATA ANALYSIS}

This study shall statistically analyze the gathered data using Smart PLS 3.0 and the latest version of IBM SPSS 25. Descriptive statistics will be utilized for the examination of statistic segment of the survey. The effect of autonomous factors on ward factors will be resolved utilizing relapse investigation. In order to examine the mediating effect of a variable for a relationship, where applicable, measurement model and structure model would be employed with the help of Smart PLS 3.0. Any other statistical test which will be applicable to data will also be used.

\section{EXPECTED CONTRIBUTION}

The research is expected to expand the scarce literature on employee performance. By showing the effect of CEO Transformational Leadership and Ambidextrous Leadership, it will enable the manager and 
leaders to curtail the effects of Organizational Ambidexterity on employee performance of the individual employees and their input for the organization.

\section{CONCLUSION}

In conclusion, the proposed framework of this initial study on ambidextrous leadership for transformational leadership shed some more light on the complex on the mediating role of organizational ambidexterity and moderating role of innovation climate, in influencing the relationship both directly and indirectly with employee performance. For that reason, the purpose of this study was to further investigate the leadership styles of managers within an IT organizations and their correlation with employee performance.

\section{References}

Andriopoulos, C., \& Lewis, M. W. (2009). Exploitation-exploration tensions and organizational ambidexterity: Managing paradoxes of innovation. Organization Science, 20(4), 696-717.

Bass, B. M. (1999). Two decades of research and development in transformational leadership. European Journal of Work and Organizational Psychology, 8(1), 9-32.

Berends, H., Smits, A., Reymen, I., \& Podoynitsyna, K. (2016). Learning while (re) configuring: Business model innovation processes in established firms. Strategic Organization, 14(3), 181-219.

Birkinshaw, J., \& Gupta, K. (2013). Clarifying the distinctive contribution of ambidexterity to the field of organization studies. The Academy of Management Perspectives, 27(4), 287-298.

Birkinshaw, J., Bouquet, C., \& Barsoux, J. L. (2011). The 5 myths of innovation. MIT Sloan Management Review, 52(2), 43.

Birkinshaw, J., Hamel, G., \& Mol, M. J. (2008). Management innovation. Academy of Management Review, 33(4), 825-845.

Bonesso, S., Gerli, F., \& Scapolan, A. (2014). The individual side of ambidexterity: Do individuals' perceptions match actual behaviors in reconciling the exploration and exploitation trade-off? European Management Journal, 32(3), 392-405

Dess, G. G., \& Picken, J. C. (2000). Changing roles: Leadership in the 21st century. Organizational Dynamics, 28(3), 1-15.

Drejer, A. (2006). Strategic innovation: A new perspective on strategic management. Handbook of Business Strategy, 7(1), 143-147.

Elkins, T., \& Keller, R. T. (2003). Leadership in research and development organizations: A literature review and conceptual framework. The Leadership Quarterly, 14(4), 587-606.

Farr, J. L., Sin, H. P., \& Tesluk, P. E. (2003). Knowledge management processes and work group innovation. In L. V. Shavinina (Ed.), The international handbook on innovation (pp. 574-586). Oxford, UK: Elsevier Science.

Garcia-Morales, V. J., Matias-Reche, F., \& Hurtado-Torres, N. (2008). Influence of transformational leadership on organizational innovation and performance depending on the level of organizational learning in the pharmaceutical sector. Journal of Organizational Change Management, 21(2), 188-212.

Gebert, D., Boerner, S., \& Kearney, E. (2010). Fostering team innovation: Why is it important to combine opposing action strategies? Organization Science, 21(3), 593-608.

Giesen, E., Riddleberger, E., Christner, R., \& Bell, R. (2010). When and how to innovate your business model. Strategy \& Leadership, 38(4), 17-26

Hamel, G. (2006). The why, what, and how of management innovation. Harvard Business Review, 84(2), 72

Horth, D. M. \& Vehar, J. (2012). Becoming a leader who fosters innovation. A White Paper. Greensboro, NC: Center for Creative Leadership. 
Horth, D., \& Buchner, D. (2009). Innovation Leadership: How to use innovation to lead effectively, work collaboratively and drive results. Greensborough, NC: Center for Creative Leadership.

Jansen, J. J., George, G., Van den Bosch, F. A., \& Volberda, H. W. (2008). Senior team attributes and organizational ambidexterity: The moderating role of transformational leadership. Journal of Management Studies, 45(5), 982-1007

Khattak, A., \& Stringer, C. (2017). Environmental Upgrading in Pakistan's Sporting Goods Industry in Global Value Chains: A Question of Progress? Business \& Economic Review, 9(1), 43-64.

Lawton, L. J., \& Weaver, D. B. (2010). Normative and innovative sustainable resource management at birding festivals. Tourism Management, 31(4), 527-536.

Loewe, P., \& Chen, G. (2007). Changing your company's approach to innovation. Strategy\& Leadership, 35(6), 18-26

Lubatkin, M. H., Simsek, Z., Ling, Y., \& Veiga, J. F. (2006). Ambidexterity and performance in small-to medium-sized firms: The pivotal role of top management team behavioral integration. Journal of Management, 32(5), 646-672

Morris, M. H., Kuratko, D. F., \& Covin, J. G. (2010). Corporate entrepreneurship \& innovation. Cincinnati, $\mathrm{OH}$ : Thomson/South-western Publishers

Mujtaba, A. (2012). Celebrating decade of excellence. Islamabad: Federal Boad of Revenue.

Nadeem, (2018) List of softwere houses in Pakistan. Retrieved from http://www.ajsoftpk.com

Nadvi, K., Thomsen, P. L., Xue, H., \& Khara, N. (2011). Playing against China: global value chains and labour standards in the international sports goods industry. Global Networks, 11(3), 334-354.

Nemanich, L. A., \& Vera, D. (2009). Transformational leadership and ambidexterity in the context of an acquisition. The Leadership Quarterly, 20(1), 19-33

O’Reilly, C.A. and Tushman, M.L. (1997). Using culture for strategic advantage: promoting innovation through social control. In Tushman, M.L. \& Anderson, P. (Eds.), Managing Strategic Innovation and Change: A Collection of Readings, 200-216. New York, NY: Oxford University Press.

O'Reilly, C. A., \& Tushman, M. L. (2004). The ambidextrous organization. Harvard Business Review, 82(4), 74-83.

O'Reilly, C. A., Caldwell, D. F., Chatman, J. A., Lapiz, M., \& Self, W. (2010). How leadership matters: The effects of leaders' alignment on strategy implementation. The Leadership Quarterly, 21(1), 104-113.

Probst, G., Raisch, S., \& Tushman, M. L. (2011). Ambidextrous leadership: Emerging challenges for business and HR leaders. Organizational Dynamics, 40(4), 326-334

Rosing, K., Frese, M., \& Bausch, A. (2011). Explaining the heterogeneity of the leadership-innovation relationship: Ambidextrous leadership. The Leadership Quarterly, 22(5), 956-974.Probst

Samad, S. (2012). The influence of innovation and transformational leadership on organizational performance. Procedia-Social and Behavioral Sciences, 57, 486-493.

Sammut-Bonnici, T., \& Paroutis, S. (2013). Developing a dominant logic of strategic innovation. Management Research Review, 36(10), 924-938. doi:10.1108/MRR-08-2013-184.

Schmitt, L. (2012). The bright stuff: The LED and Nick Holonyak's fantastic trail of innovation. Chicago, IL: Milton Feng.

Sharafat, A. L. I., Rashid, H., \& Khan, M. A. (2014). The role of small and medium enterprises and poverty in Pakistan: An empirical analysis. Theoretical and Applied Economics, 18(4 (593), $67-$ 80.

Shavinina, L. V. (2011). Discovering a unique talent: On the nature of individual innovation leadership. Talent Development \& Excellence, 3(2), 165-185.

Soken, H.N., \& Kim Barnes, B. (2014). What kills innovation? Your role as a leader in supporting an innovative culture. Industrial and Commercial Training, 46(1), 7-15.

Somech, A. (2006). The effects of leadership style and team process on performance and innovation in functionally heterogeneous teams. Journal of Management, 32(1), 132-157.

Torugsa, N. A., O'Donohue, W., \& Hecker, R. (2012). Capabilities, proactive CSR and financial performance in SMEs: Empirical evidence from an Australian manufacturing industry sector. Journal of Business Ethics, 109(4), 483-500. 
West, M. A., \& Farr, J. L. (1990). Innovation at work. In M. A. West \& J. L. Farr (Eds.), Innovation and creativity at work. Psychological and organizational strategies, 3-13. Chichester, UK: Wiley.

Zacher, H., \& Rosing, K. (2015). Ambidextrous leadership and team innovation. Leadership \& Organization Development Journal, 36(1), 54-68. 